\title{
Errar principios de amor, una enredada y desconocida comedia de Pedro Rosete
}

Elisa Domínguez de Paz

Universidad de Valladolid (España) 



\title{
Errar principios de amor, una enredada y desconocida comedia de Pedro Rosete
}

\section{Errar principios de amor, a tangled and unknown comedy by Pedro Rosete}

Elisa Domínguez de Paz

Universidad de Valladolid (España)

elisa@fyl.uva.es

Fecha de recepción: 22 de octubre de 2019

Fecha de aceptación: 16 de agosto de 2020

\section{Resumen}

El objetivo de este trabajo es el de estudiar la comedia de enredo, Errar principios de amor (1646), de Pedro Rosete Niño. Se trata de una pieza muy poco conocida dentro de su corpus teatral y como ocurre con otras comedias del citado dramaturgo, esta ha quedado arrumbada al más injusto de los olvidos. Se trata de textos que es preciso recuperar, pues representan, sin duda alguna, un valor en nuestro rico patrimonio cultural y teatral.

Palabras clave: Rosete, Pedro (1608-1659?); Enredo; Amor; Celos; Escenografía.

\begin{abstract}
This article aims to study a comedy of intrigue, Errar principios de amor (1646), by Pedro Rosete Niño, a very unknown play within his own theatre corpus. As it is the fact with other comedies by the same playwright, this text has suffered the most unjust neglect. Consequently, this is a situation that needs to be reverted, as his works do represent, beyond any doubt, a valuable example of our rich cultural and theatrical heritage.
\end{abstract}

Keywords: Rosete, Pedro (1608-1659?); Intrigue; Love; Jealousy; Scenography. 


\section{EL AUTOR}

Apenas se conocen datos de la biografía de Pedro Rosete Niño (1608-1659?), a pesar de ser un dramaturgo conocido y reconocido en el panorama teatral del siglo XVII (Barrera, 1860, pp. 344-345); (Urzáiz, 2002). Enríquez Gómez lo cita en el prólogo del Sansón Nazareno, publicado en 1656:

En mi tiempo, dejado aparte el Adam de la comedia, que fue Lope, hubo lucidisimos poetas. [...] No olvido a don Francisco de Rojas, ni a don Pedro Rosete, Gaspar de Ávila, don Antonio de Solís, don Antonio Cuello y otros muchos, que con acierto grande escribieron comedias (Enríquez Gómez 1656, h. 3r-v).

Rosete estudió en la universidad de Alcalá de Henares. Cultivó el género poético participando en 1637 en la Academia Burlesca del Buen Retiro en honor a Felipe IV con cuatro octavas; en 1639 escribió unos tercetos, "A la muerte del doctor Juan Pérez de Montalbán", incluidos en el volumen titulado, Lágrimas panegíricas a la temprana muerte del doctor Juan Pérez de Montalbán, que se publicó en 1639 (f.110r-v); también compuso una elegía en 1645 a la muerte de doña Isabel de Borbón.

En cuanto a su faceta como dramaturgo, Rosete es autor de un nutrido corpus teatral que se gestó, en unos casos, de manera individual y, en otros, participó en comedias colaboradas (Huerta et al., 2005). En el Vejamen de la Academia de Madrid, escrito por Cáncer hacia 1649, se habla de él como de un hombre enfermo, con poca suerte en las tablas, y con alguna desgracia en su vida. Efectivamente, parece que el estreno en 1641 de su comedia costumbrista, hoy perdida, Madrid por de dentro, donde -según el cronista Pellicer- "pintaba la vida de tahúres, rufianes, mujeres de mal vivir, y gallinas con apariencia de valientes" le llevó aparejado una paliza de la que resultó malherido (Barrera, p. 344). Asimismo, Cáncer menciona que escribió con él y otro amigo, acaso Sebastián Rodríguez de Villaviciosa, la comedia San Isidro labrador (colaborada con Cáncer). Lo que es cierto es que su corpus dramático es muy variado y se compone de comedias de enredo (Ello es hecho; Allá se verá; Errar principios de amor; Mira al fin; La más honrada cautela; Acertar pensando errar); comedias de tema histórico (Pelear hasta morir; Todo sucede al revés. La traición de Galisteo y engaño del rey de Frigia, hoy desaparecida, Los bandos de Vizcaya; La conquista de Cuenca y primer dedicación a la Virgen del Sagrario), comedias hagiográficas (La Rosa de Alexandría, Santa Catalina (representada en la Montería de Sevilla, en 1641); Solo en Dios la confianza), una comedia caballeresca (La gran torre del orbe, Amadís de Grecia) y una mitológica (Píramo y Tisbe). De igual modo se le atribuye una pieza de moros y cristianos titulada El triunfo del Ave María.

Más fértil fue su obra en colaboración entre la que destacan los siguientes títulos: El arca de Noé (con Cáncer y Martínez de Meneses y representada en la Montería 
sevillana en 1644); El rey don Enrique el Enfermo (con Zabaleta, Martínez, Villaviciosa [D.S.], Cáncer y Moreto); El bandolero Solposto (colaborada con Cáncer y Rojas. La segunda jornada es de Rosete); El mejor representante, San Ginés (con Cáncer y Martínez de Meneses); Julián y Basilisa (con Cáncer y Huerta); Lo que merece un soldado (comedia disputada entre Moreto y Godínez); La luna africana (con Luis y Juan Vélez, Belmonte, Alfara, Moreto, Martínez de Meneses, Sigler de Huerta y Cáncer); Hacer su papel de veras (1 141 ) o Chico Baturi y siempre es culpa la desgracia (con Cáncer y Antonio Huerta. La tercera jornada es de Rosete) entre otras piezas. Además, compuso dos entremeses: $E l$ gigante, escrito en colaboración con Cáncer y el Entremés de las burlas del Doctor a Juan Rana compuesto para unas fiestas celebradas en 1655 en los jardines del Buen Retiro. Vemos, pues, cómo Rosete colaboró con dramaturgos relevantes en el panorama teatral del siglo XVII, lo cual es indicativo de que este era un escritor bien considerado por sus contemporáneos.

\section{ERRAR PRINCIPIOS DE AMOR}

\subsection{Trama}

La acción dramática se sitúa en la ciudad de Toledo y desde la primera escena aparece el equívoco. Se trata de hacer una presentación ante el espectador de los personajes que van a intervenir en el embrollo teatral y plantear sus conflictos amorosos. La comedia empieza con las palabras de Enrique, que se lamenta de la confusión de su criado Frisón al entregar a Estefanía la carta de amor que él había escrito a su amada Leonor.

A continuación, Carlos pide consejo a su amigo Enrique para que le ayude a solucionar la cuita amorosa que padece, pues en Sevilla Carlos conoció a Luisa y ambos se enamoraron, pero el padre de la dama ya tenía concertado para su hija el matrimonio con Fernando Pantoja. Carlos, movido por los celos, entabló una pendencia con el citado pretendiente sevillano e hiriéndole, se vio obligado a abandonar la ciudad hispalense.

En Toledo, y por la conversación que mantienen las damas Leonor y Estefanía, vemos que la primera ama a Carlos y no a Enrique y la segunda bebe los vientos por Enrique sin ser correspondida. La jornada I concluye con la petición de ayuda que le hace Enrique a Carlos para que interceda por él ante Leonor de quién está profundamente enamorado.

Esta jornada es la más teatral y las más ampliamente trabajada, puesto que aquí se materializa todo el conflicto de amores cruzados y no correspondidos. Es el 
acto en el que todos los recursos que caracterizan la llamada comedia de enredo: amor-honor-celos, nocturnidad, confusión de identidades, cobran pleno sentido dramático.

Al comienzo aparece en escena una apenada Luisa, la cual reniega de su condición de mujer al sentirse abocada, por imposición paterna, a contraer matrimonio con Fernando. Los criados, por su parte, intervienen para relajar la situación y se mofan de las cuitas de sus amos exponiendo su concepto materialista del amor.

A continuación, salen a escena las damas, Leonor, Luisa y Estefanía y todas ellas se quejan del papel irrelevante que juega la mujer en una sociedad de perspectiva y dominio masculinos.

Seguidamente en una escena nocturna Carlos, por mandato de su amigo Enrique, va a entregar una carta a Leonor; esta sale al balcón y, al ver a Carlos, supone que viene a declararle su amor. Mientras Luisa, que está al paño, oye la conversación entre ellos y cree ser víctima de una traición por parte de Carlos. El enredo se complica porque, Fernando, que se halla también al paño, al otro lado del escenario, oye de igual modo la conversación, pero cree que la dama es Luisa con lo cual, al sentirse traicionado, decide romper el compromiso de boda con ella y pedir la mano de Leonor. En este mar de confusiones varias, Luisa arroja una banda que va a parar a los pies de Carlos y también un papel que recoge Fernando. Leonor sospecha que anda por ahí Luisa y le dice a Carlos que se vaya.

En la siguiente escena, Enrique le declara su amor a Leonor y le explica cómo el criado Frisón ha sido el origen de todo el enredo, pues, en realidad, la carta que le entregó a Estefanía iba dirigida a ella.

Por su parte, Luisa, de manera hipócrita, le dice que le cuente la pena amorosa que siente por Carlos.

La jornada concluye con los reproches airados de Luisa hacia Carlos porque lo considera ingrato y desleal. Fernando ratifica su decisión de abandonar a Luisa.

\section{III}

El último tramo argumental de la comedia es el más breve y tiene como principal objetivo deshacer el enredo y recolocar las emociones para lograr un final feliz. Así, Leonor le confiesa a Luisa que no va a entrometerse en la relación de aquella con Carlos y que va a aceptar a Fernando como esposo. A continuación, Carlos habla con Leonor y le explica que su verdadero amor es y será siempre Luisa. Esta, que escucha al paño la conversación, sale a escena y ambos, Luisa y Carlos, se declaran su mutuo amor. Enrique le propone a Estefanía matrimonio y la comedia termina con una sentencia del criado Frisón en la que afirma que el mayor desacierto de los amos es entregar papeles de amor a sus criados, pues o publican sus secretos o los pierden descuidados. 


\subsection{Género y estructura}

Errar principios de amor cuenta con tres testimonios textuales; se editó por primera vez en Valencia (1646) en la Parte LVII de Doce comedias de diferentes autores, a costa de Juan Sonzoni. No se sabe la fecha exacta de su composición, que habría de situarse en el arco de tiempo que va de 1628, año en que Rosete comienza a escribir para los teatros de Madrid, y el año de la publicación valenciana de 1646. Se documenta una edición en Lisboa, en 1652, en la Parte IV de Doce comedias, las más grandiosas que hasta ahora han salido de los mejores y más insignes poetas, a costa de Juan Leite. Por último, existe una suelta publicada en Sevilla, S.A, a costa de Francisco de Leefdael. Nada se conoce acerca de la fama y fortuna de la obra, pues ante la escasa documentación que tenemos, no se puede valorar su posible éxito o fracaso a lo largo del tiempo; esto nos obliga a entrar en el terreno de la hipótesis y aventurar que, o bien, la pieza se perdió en el arcano de los tiempos -algo nada extraño en la época-y eso explicaría el nulo recorrido teatral de la misma, o bien, la pieza no respondió a las expectativas del lector y espectador del tiempo. Creo que esto último es más improbable porque genéricamente la comedia de Rosete tiene una construcción canónica como la de cualquier texto de enredo, de los muchos que proliferaron en el teatro barroco: amor, celos, honor, papel, equívocos, tapadas, amores cruzados y no correspondidos, celos y, por supuesto, un happy end al uso esperado donde cada uno de los personajes se empareja con quien quiere o con quien puede (Gutiérrez Gil, 2012). La comedia de enredo fue muy demandada por el público, su éxito fue incuestionable en el siglo XVII y se proyectó hasta bien entrado el siglo siguiente. El subgénero comenzó a desarrollarse antes de 1620 gracias a autores como Lope de Vega o Tirso de Molina . Se trata de un tipo de comedia que suele identificarse como de capa y espada (Arellano, 1999); (Menéndez Pelayo, 1941, p. 270); (Serralta, 1998, pp.125-135) llegando a considerarse como sinónimos ambos términos. Bances Candamo en Teatro de los Teatros confirma esta simbiosis:

Las [comedias] de capa y espada son aquéllas cuyos personajes son sólo caballeros particulares como Don Juan o Don Diego, etcétera, y los lances se reducen a duelos, a celos, a esconderse el galán, a taparse la dama y, en fin, a aquellos sucesos más austeros de un galanteo (Duncan Moir, 1970, p.33).

Juan de la Cueva en El ejemplar poético (1616) comenta lo siguiente:

Mas la invención, la gracia y traza es propia

a la ingeniosa fábula de España, no cual dicen los émulos impropia.

Cenas y actos suple la maraña tan intrincada y la soltura de ella, inimitable de ninguna extraña. 
Es la más abundante y la más bella

en facetos enredos y en jocosas

burlas, que darles igual es ofendella (Cf, Zugasti,1 997, p. 115)

El Diccionario de Autoridades define el enredo en la tercera acepción como:

Enlace y trabazón artificiosa de unas cosas con otras, como el de las comedias y óperas de los teatros, mezcladas de varios lances y tejidas con arte para tener suspenso al auditorio.

Es cierto que el embrollo está presente tanto en lo trágico como en lo cómico, pues "el teatro es enredo y lo necesita para existir" (Zugasti, 1997, p. 116). La intriga y los engaños que urden los distintos personajes en busca de sus objetivos, dan lugar a un tipo de comedia que, en la mayoría de los casos, siendo de capa y espada, encadena episodios y situaciones enmarañadas.

Desde el punto de vista de organización de la trama, Errar principios de amor, presenta una laberíntica estructura, pero bien trabada; Rosete introduce en la trama seria, de manera singular, tres galanes y tres damas sobrepasando en número el esquema más habitual en las piezas de enredo, que solían emplear casi siempre la variante de dos galanes y dos damas. Aunque la fórmula hexagonal de personajes no era muy común, tampoco resultaba extraña e incluso algunos dramaturgos como Lope de Vega la amplían, ahí tenemos como ejemplo, El acero de Madrid, con cuatro galanes y tres damas (Couderc, 2003); posteriormente la comedia de enredo adoptó la variante pentagonal de tres galanes y dos damas, dando lugar al galán suelto, así llamado porque es el único que al final de la obra queda sin pareja ; Este personaje se convierte en precursor del figurón (Serralta 1988, p.91). La comedia de Rosete presenta dos tramas principales y una más secundaria:

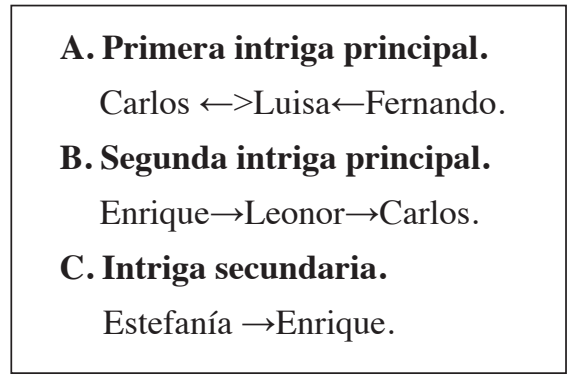

El núcleo fundamental lo constituye la terna $\mathrm{A}$, donde una mujer es amada por dos galanes en paralelo antitético con la estructura B; aquí Leonor es amada por un solo galán, al que no corresponde $\mathrm{y}$, a su vez, ella suspira por Carlos que ama a Luisa, con lo cual se produce una interferencia con A, que resulta muy eficaz para el desarrollo del enredo. La estructura $\mathrm{C}$ es la más endeble, desde el punto de vista teatral; su razón de ser estriba en la necesidad de lograr un equilibrio final con 
unas bodas múltiples. La dama $\mathrm{A}$ es la única que consigue casarse con el hombre al que ama, mientras que $\mathrm{B}$ y $\mathrm{C}$ lo hacen, sin amor, con los galanes que al final quedan disponibles y como un mal menor para ellas; ellos también salen airosos del enredo, pues casándose, evitan quedar como galanes sueltos. En cuanto a las figuras del donaire, Frisón e Inés, no presentan entre ellos ningún tipo de intriga amorosa. Vemos, por tanto, cómo Rosete, que pertenece a la generación de Calderón, intensifica el conflicto; esto no tiene por qué dañar la originalidad de la comedia, al contrario de lo que afirma McKenzie, y cuyo juicio no comparto en este caso concreto, ya que entiende que esta generación de dramaturgos explotó tanto los recursos del enredo que produjeron comedias "estropeadas por un convencionalismo insistente y excesivo" (Mackenzie,1983, p. 83). Errar principios de amor, como se ha visto en la descripción de la trama, presenta un universo poblado por galanes y damas que viven situaciones de amores cruzados, las cuales son muy efectivas desde el punto de vista teatral, pues no hay que olvidar que: "amor, ingenio y mujer, en fórmula calderoniana, mueven a menudo el mecanismo del enredo" (Navarro Durán, 2003, p. 137). Esto lo entendió muy bien Rosete y lo aplicó ingeniosamente en su obra.

\subsection{Dramatis personae}

Errar principios de amor es una comedia en la que los personajes tienen una importancia fundamental porque su conducta marca el hilo de la acción dramática. Rosete plantea, desde los primeros versos, el origen del embrollo argumental fundamentado en el equívoco y muestra al "culpable" del mismo: el criado Frisón, a quien encomienda que entregue a Leonor un papel de amor, pero el criado se lo da a la dama equivocada, Estefanía. Ahora bien, se trata de una culpabilidad relativa por parte del criado, pues tal vez su amo debiera haberse aplicado aquellas palabras que, a modo de moraleja, pronuncia el personaje de doña María de la comedia, Bien vengas mal si vienes solo (1635), de Calderón cuando le dice a doña Ana, a quien le entrega las cartas de amor que se ha escrito con don Juan: "y no es discreto un papel, / sino en manos de su dueño" (I, vv. 469-470). Enrique ha "pecado" aquí de un exceso de confianza en su criado, con lo cual le toca asumir las consecuencias de la mala cabeza de Frisón. El papel es un recurso muy útil usado en el teatro del siglo XVII, especialmente en las piezas de enredo ${ }^{1}$, pues cayendo en poder de quien no debe, acarrea unas consecuencias que revuelven la acción y que, sin duda, aseguran el entretenimiento del espectador (Higashi, 2013).

1 Se trata de un procedimiento que se empleó mucho en el teatro del siglo XVII; Calderón concretamente lo usó bastante en comedias tan conocidas como, La dama duende y Casa con dos puertas, mala es de guardar, ambas de 1629; Con quien vengo, vengo (1630); Mañanas de abril y mayo (1633; Bien vengas mal si vienes solo (1635); El escondido y la tapada (1636); No hay burlas con el amor (1637) entre otras obras. 


$\begin{array}{ll}\text { FRISÓN } & \begin{array}{l}\text { Pues ya tu papel le di } \\ \text { a la bella Estefanía. }\end{array} \\ \text { ENRIQUE } & \text { ¿Hay desdicha semejante? } \\ & \text { No lo repitas Frisón, } \\ & \text { porque yerros de amor son } \\ & \text { desdoros en un amante. (I, vv. 30-36) }\end{array}$

Lo escrito en la misiva hace concebir ilusiones a Estefanía, cuando en realidad Enrique ama a Leonor, aunque no es correspondido por esta. Entonces el papel adquiere aquí el significado de prólogo al convertirse, no solo en la excusa perfecta para presentar a los personajes principales implicados en la trama y para dar a conocer al público las claves de amores en las que se ven envueltos, sino también para orientarlo acerca de la directriz que va a tomar el enredo. Esto se aprecia muy bien con el encuentro de Carlos y Enrique, al comienzo de la obra, cuando hablan de las damas que causan sus respectivos desvelos amorosos:

$\begin{array}{ll}\text { CARLOS } & \text { En una casa de campo } \\ \text { puse en cobro mi persona } & \text { donde hallé albergue sagrado } \\ \text { en una mujer piadosa. } & \text { Supo de mí doña Luisa } \\ \text { y cuando el sol arrebola } & \text { los balcones del Oriente, } \\ & \text { con unas luces dudosas } \\ \text { entró a verme en el jardín, } & \\ \text { tan bizarra y tan hermosa. } & \quad[\ldots] \\ & \text { El padre de doña Luisa, } \\ \text { la playa pisó arenosa } \\ \text { del tan celebrado Cádiz } \\ \text { en las antiguas victorias. } \\ \text { Llegó a Sevilla y trató } \\ \text { de dársela por esposa } \\ \text { a un hijo desta ciudad. } \\ \text { [...] } \\ \text { Esta es valeroso Enrico } \\ \text { el progreso de mi historia, } \\ \text { la causa de mis desvelos, } \\ \text { la ocasión de mis congojas. (I, vv.253-412) }\end{array}$ 


$\begin{array}{ll}\text { ENRIQUE } & \text { Si yo llegara a alcanzar } \\ & \text { favores de esa mujer [Leonor], } \\ & \text { ni tengo más que querer, } \\ & \text { ni tengo más que buscar. (I, vv.689-692) }\end{array}$

Otras veces el papel agudiza el conflicto amoroso, pues contribuye a exacerbar los celos femeninos en lugar de apaciguarlos. Así sucede cuando, Carlos, -que es el mensajero de Enrique para que le entregue de su parte la carta a su amada Leonor-es observado al paño por Fernando, que se halla a un lado del escenario, y por Luisa, que está también al paño y al otro lado del tablado; es de noche y ambos presencian el encuentro de galán y dama, creyendo equivocadamente que Carlos va a cortejar a Leonor. Se oyen ruidos y Carlos se va, pero pierde el susodicho papel que recoge Fernando y se lo da a Luisa:

\begin{tabular}{|c|c|}
\hline ISA (lee) & $\begin{array}{l}\text { Mi bien (Ap. que blanda lisonja) } \\
\text { y señora de mis ojos } \\
\text { (Ap. Que acierte a medir su pluma } \\
\text { afectos tan amorosos) } \\
\text { como no te puedo ver. } \\
\quad[\ldots] \\
\text { Y en estas ansias me miro } \\
\text { tan fuerte de mí y tan loco, } \\
\text { que muchas veces me pierdo } \\
\text { y pocas veces me cobro. } \\
\text { Ap. (Si fuera Carlos amante, } \\
\text { al paso que es ingenioso, } \\
\text { si hallara más el deseo, } \\
\text { ni yo esperara más logro). } \\
\quad[. . .]\end{array}$ \\
\hline
\end{tabular}

(II, vv, 1960-2015)

Vemos cómo Rosete maneja muy bien los apartes y consigue con ello que se establezca una complicidad con el auditorio, el cual, al estar a un nivel de conocimiento superior al de los personajes, le permite, de alguna forma, controlar la acción.

En cuanto a las damas, tienen en esta comedia una gran importancia, a pesar de que las reglas sociales que restringen las libertades de la mujer -como el no poder elegir en cuestiones de amor- hacen que el protagonismo involuntario de estas damas 
sea el reflejo del desfavorecido papel que la sociedad del siglo XVII, de perspectiva claramente masculina, les asigna; se espera de ellas que sean dóciles, obedientes y recatadas (Vigil, 1986, pp. 18-24). El teatro barroco ofrece muchos ejemplos de ello. Sirvan a este respecto las conocidas palabras que pronuncia Otavio, padre de Finea y Nise, en La dama boba de Lope sobre lo que debe ser el modelo tradicional de mujer perfecta, sumisa y recatada, y que resumen fielmente la mentalidad del hombre barroco respecto a la cuestión femenina.

ETAVIO la discreción de una casada
en amar y servir a su marido;
en vivir recogida y recatada,
honesta en el hablar y en el vestido;
en ser de familia respetada,
en retirar la vista y el oído,
en enseñar los hijos, cuidadosa,
preciada más de limpia que de hermosa. (I, vv. 225-232)

En efecto, las damas son plenamente conscientes de lo que supone ser mujer en el siglo XVII; viven en una realidad inscrita en un código social establecido que las lleva, muchas más veces de las deseadas, a hipotecar su felicidad para acatar la voluntad paterna. En esta comedia es don Pedro, padre de Luisa, el que actúa como paterfamilias; su participación es escasa, pero esto no implica que su "existencia" no se note a lo largo de la obra; todo lo contrario, está muy presente como entorpecedor de las expectativas amorosas de su hija, al concertarle un matrimonio con Fernando que ella no desea. Los padres de Leonor y Estefanía no aparecen en escena y tampoco es necesario, pues la conducta social de las damas es bien reveladora de la educación recibida por la mujer en una sociedad en la que el padre tenía la primera y la última palabra sobre el destino amoroso de sus hijas.

LUISA ¿Qué pueda la obediencia dar estado
y quiera sujetar el albedrío,
por elección ajena siendo mío
a una fineza y a un amor comprado?
(...)
Rigor es este de enemiga suerte
, que a las mujeres hace desdichadas,
y a mí me tiene muerta de temores,
y aún fuera corto mal la misma muerte,
pero en mis ansias es muerte doblada,
morir de penas y vivir de amores. (II, vv. 950-963) 
El dramatismo e impotencia que Luisa siente se ve corroborado también por Estefanía cuando exclama: "iQué desdichadas somos las mujeres!" (v.1326), aunque esta represente el tipo de fémina que acepta las normas sociales de la época; entiende que deben cumplirse a rajatabla, pues antes que el amor está la salvaguarda del honor familiar de la que la mujer es depositaria y también víctima de tan peculiar status quo. Son damas bellas, audaces, enamoradas y conscientes de que viven en un mundo dominado por hombres, lo cual no necesariamente significa que acepten de buen grado su situación. Ahí está, por ejemplo, el caso de la viuda doña Ángela de La dama duende de Calderón, que vive "encarcelada" por sus hermanos y se resiste a aceptar esta situación impuesta por la norma social de la época, muy dura con las mujeres solteras y casadas y todavía más estricta con las viudas:

\author{
¡Válgame el cielo! Que yo \\ entre dos paredes me vea \\ donde apenas el sol sabe \\ quien soy, pues la pena mía \\ en el término del día \\ ni se contiene ni cabe (I, vv, 379-384)
}

A menudo las damas ven truncadas sus expectativas amorosas, como ocurre en Errar principios de amor, en unos casos, porque deben cumplir las decisiones tomadas por el padre respecto a su futuro sentimental, en otros, porque tienen que luchar por un amor no correspondido, como les sucede a Leonor y Estefanía, o finalmente, porque es la dama la que directamente rechaza a quien no ama:

$\begin{array}{ll}\text { LEONOR } & \text { Vete, vete don Enrique, } \\ & \text { vete fingido engañoso, } \\ & \text { que bastan mis penas, sin que } \\ \text { me las vengas a crecer } \\ \text { con cautelosos ardides. (II, vv. 1791-1795) }\end{array}$

Del juego de amores cruzados y no correspondidos nacen los celos, tanto en galanes como en damas; Rosete proporciona en su comedia varios ejemplos, de los cuales cito algunos: en primer lugar, el que afecta a Carlos cuando conoce, a través de la criada Inés, que el padre de su amada Luisa va a casarla con Fernando.

$\begin{array}{ll}\text { CARLOS } & \text { Hoy, Juana, me aseguró } \\ \text { que trata tus desposorios } \\ \text { con más violencia tu padre, } \\ \text { y vengo, vengo tan loco, } \\ \text { tan muerto vengo, que apenas, }\end{array}$




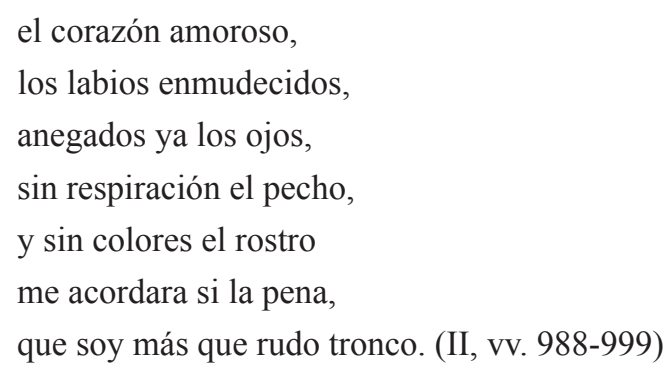

En segundo lugar, está Luisa que se enfrenta con Carlos porque cree que no es ella la elegida de su corazón.

$\begin{array}{ll}\text { LUISA } & \text {...Rompo } \\ \text { las mentiras, que me has dicho, } \\ \text { los agravios, los oprobios } \\ \text { que por tu causa padece } \\ \text { mi proceder generoso. } \\ \text { Rompo toda mi deshonra, } \\ \text { tus estilos cautelosos, } \\ \text { las lisonjas de tu pluma, } \\ \text { que en mi honor hacen destrozos. }\end{array}$

Por último, vemos los celos de Leonor que no se siente correspondida por Carlos

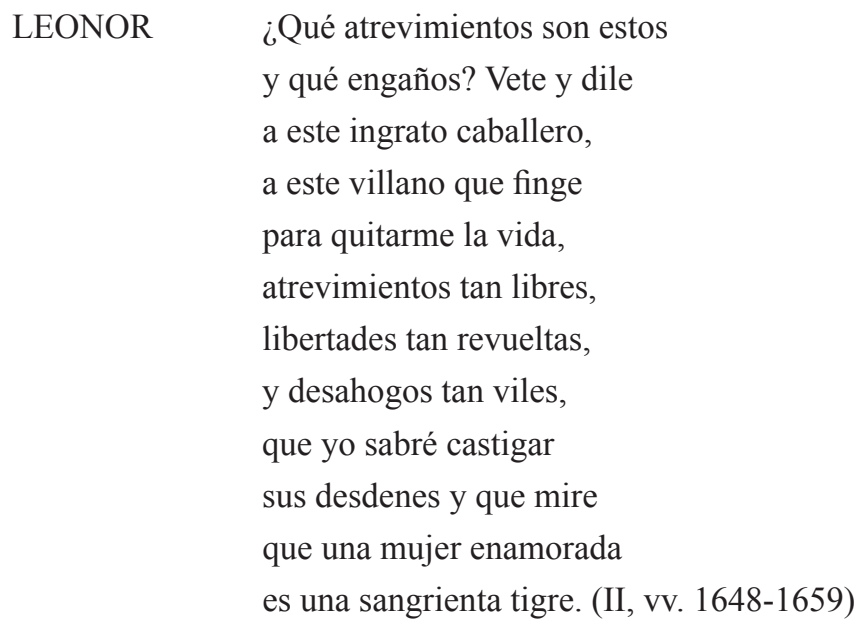


Está claro que solo el ingenio y la astucia de estas mujeres inteligentes es el medio más eficaz para lograr llevar a buen término sus intereses amorosos, al menos en el ámbito teatral, algo que no solía ocurrir en la realidad donde el rol de la mujer quedaba circunscrito al de esposa y madre exclusivamente, sin ninguna relevancia social ni legal. El teatro-resulta obvio que no podemos hablar de feminismo en el contexto de la época- viene así a compensar a las mujeres permitiéndoles "ejercer un control sobre el mundo dominado por hombres en el que están obligadas a vivir" (Wardropper, 1978, p. 226). Pura licencia teatral, muy alejada de lo que ocurría en la sociedad.

En cuanto a las figuras del donaire, Rosete también les confiere un papel relevante; su misión aquí consiste en relajar al espectador de las tensiones originadas en la acción "seria"; se mueven en un universo que es el contrapunto de sentimientos, mentalidad de vida y costumbres de sus amos. Frisón e Inés están dotados de un gran ingenio verbal y su actitud ante la vida adquiere un carácter festivo que los distancia, social y mentalmente, del mundo representado por sus amos; por ello no extraña el concepto materialista que tienen del amor, tan distinto y tan distante, del que tienen los señores.

INÉS<smiles>C1=[AlH]C[AlH]1</smiles>

Porque he hallado por cuenta, que en el mal siglo que corre, solo el dinero socorre y solo el plato sustenta, y así quisiera trocar, si con atención lo miro, en dineros el suspiro, y la fineza en manjar.

FRISÓN Pues yo de otro parecer estoy (con verdad te hablo), pues da de comer al diablo quien sustenta una mujer y es cosa que mucho pesa en verano, y en invierno, por sustentar el infierno, no sustentarme en la mesa. Y nunca me ha parecido en el amante cordura, por lograr una hermosura, no lograr un buen vestido. (II, vv. 1119-1138) 
Los comentarios del gracioso evidencian el conocimiento que tiene del enredo; expresa su punto de vista sobre la vida con un llamativo tono de seguridad, que contrasta con la vulnerabilidad, en cuestiones amorosas, que muestran los galanes y damas. A menudo los criados, y especialmente Frisón, hacen intervenciones de carácter escatológico, pues era esta una apuesta segura para provocar la hilaridad entre el público.

$\begin{array}{ll}\text { FRISÓN } & \text { ¡Qué traza para atender } \\ \text { el buen gusto de mis chistes! } & \text { Y para que mis donaires } \\ & \text { la obligaran a reírse: } \\ & \text { luego sentí en el olor, } \\ & \text { que no era Inés y la quise } \\ & \text { preguntar cómo chillaban } \\ & \text { tanto aquellos faldellines. (II, vv. 1782-1789) }\end{array}$

El humor del gracioso se usa en ocasiones para tapar algún aspecto de carácter sexual que pudiera ser captado por el ojo perspicaz del censor:

FRISÓN $\quad \begin{aligned} & \text { Al oído de la ingrata, } \\ & \text { soné el bolsillo de plata } \\ & \text { y ella quitando el capote, } \\ & \text { volvió la cara al cogote } \\ & \text { y abrió la mano de gata. } \\ & \quad[\ldots] \\ & \text { Hice en efecto gran risa } \\ & \text { y el amor que se desliza, } \\ & \text { allí prometer me hizo, } \\ & \text { que si soy caballerizo, } \\ & \text { será mi caballeriza. (I, vv. 754-778) }\end{aligned}$

En otro momento de la obra el gracioso se alza como una voz, eso sí nada autorizada, para satirizar a la mujer con comentarios que revelan el prosaísmo que caracteriza su pensamiento sobre cuestiones de amor. De igual modo, las palabras jocosas del criado respecto a los personajes protagonistas, y en especial sobre los galanes, contribuyen, además de ridiculizarlos, a inculcar en el espectador una manipulada imagen de ellos. Es decir, el dramaturgo se sirve de la mirada crítica del 
criado para hacerle al espectador una interpretación guiada de la obra. Así cuando el criado Frisón se refiere en un aparte a las sentidas palabras de Carlos, al expresar las dificultades que encuentra su amor por Luisa, lo califica como hombre de poca enjundia:

FRISÓN $\quad$ ¡Ay tal hablar! Con no poca
propiedad me parecía
jugador de tropelía,
que echa cintas por la boca,
porque tal mudar semblantes,
tal turbarse y serenar,
tal atar y desatar,
tal poner y quitar guantes. (I, vv. 441-448)

Rosete, en fin, sabe que el fin primordial del teatro es divertir al espectador; para ello se sirve de todos los mecanismos teatrales a su alcance y los aplica en esta comedia de manera funcional, midiendo los tiempos entre la tensión y la jocosidad dramáticas.

\subsection{Recursos escenográficos}

Como ya he dicho anteriormente, no tenemos documentación alguna de la posible representación de Errar principios de amor, lo cual no permite suponer, de manera tajante, que la obra no se llevara a las tablas, sino que no disponemos de los datos precisos que nos permita afirmar este hecho con rotundidad. La comedia tiene una escasez de acotaciones escénicas que hace difícil imaginar su construcción escenográfica, pero, sin embargo, sí incluye referencias intratextuales y parateatrales acerca de cómo pudo ser su hipotética representación. La acción se ubica en Toledo y en la referencia temporal del hic et nunc del espectador. Se trata de buscar una cercanía con el público y un realismo cotidiano que penetre de manera divertida en los entresijos de la sociedad española de esa época a través del comportamiento de los personajes. Asimismo, se observa una concentración temporal, pues la acción se desarrolla en dos días, marcados en el texto por las alusiones que se hacen a la luz y a la noche y que se repiten al día siguiente. Los amores cruzados y prohibidos entre galanes y damas posibilitan la aparición de escenas nocturnas, que generan variados conflictos, ya que unos personajes hablan con los otros creyendo que son quienes no son en la realidad y creándose, por tanto, continuos equívocos muy efectistas desde el punto de vista teatral (Lobato, 2011). Fernando oye voces de dos personas que están hablando y cuya identidad desconoce como consecuencia de la oscuridad: 
FERNANDO pues la noche da lugar con su oscura confusión (II, vv.1430-1431)

Un poco más adelante vuelve a ser Fernando el que da la clave temporal y de sus palabras se deduce que estamos ante una nueva jornada:

Es que anoche soñé o vi

$$
\text { que hablabas [...]. (II, vv.1917-1918) }
$$

Para escenificar la oscuridad en los corrales de comedias aprovechaban la luz del día ${ }^{2}$, de ahí que se recurriera a mecanismos tanto verbales como escenográficos cuando la acción teatral requería simular la noche cerrada pues:

Uno de los recursos más utilizados para señalar que el tiempo dramático de la obra transcurría de noche o a oscuras era que los actores portasen velas (espacio interior) o teas (espacio exterior) para reflejar así la situación que se representaba en escena. Se trata de una convención dramática que el espectador del corral aceptaba con naturalidad y que se encuentra con frecuencia en la representación de este tipo de obras (Alfonso, 2012, pp. 587).

Las referencias gestuales y verbales de los personajes a la falta de luz contribuirían también a crear una atmósfera de "credibilidad" harto complicada para el espectador, habida cuenta de que en la realidad las funciones teatrales se hacían a plena luz del día ${ }^{3}$.

El espacio escénico de Errar principios de amor es, como solía ocurrir en comedias de enredo, francamente reducido, pues más que lo visual, que pudiera distraer al espectador, importaba sobre todo no perder el hilo del enredo. (Ruano, 2000, pp. 138-139); (Antonucci, 2002). Rosete circunscribe el uso escenográfico a las abundantes entradas y salidas de los personajes por las puertas laterales del escenario que, además de delimitar los espacios interiores, como son la casa de Luisa, Leonor y Enrique respectivamente, y exteriores, como la calle, contribuyen a enmarañar la trama accional. De igual modo resulta muy interesante el desfase espacial que se produce entre el escenario real y el espacio teatral, que afecta a los distintos niveles de recepción: el del público, por un lado, y el de los personajes que intervienen en la acción, por el otro. Al comenzar la obra se dice, Salen don Enrique y Frisón lacayo, el espectador entiende que el personaje sale a escena, pero teatralmente está entrando en la casa de Enrique, pues el espacio interior doméstico, del que no se menciona ningún tipo de mobiliario, se convierte en el eje de las

2 En invierno el horario de representación era de 14.00-17.00 y en verano de 16.00-21.00 aproximadamente.

3 En la actualidad es mucho más fácil conseguir este efecto, ya que se dispone de medios técnicos visuales apropiados capaces de lograr la simulación del día y de la noche. 
sucesivas acciones que generan el conflicto. Este tipo de situaciones están muy repetidas en esta comedia: Vase Fernando, y salen doña Leonor y doña Estefanía con mantos. Aquí es Fernando el que se va de la casa de Luisa y entran en la misma las damas citadas. En otras ocasiones el espacio exterior e interior, se crea a través de la referencia verbal; este mecanismo, bastante frecuente en comedias de enredo, contribuye a paliar una escenografía precaria y la falta de decorados estables en los corrales de la época.

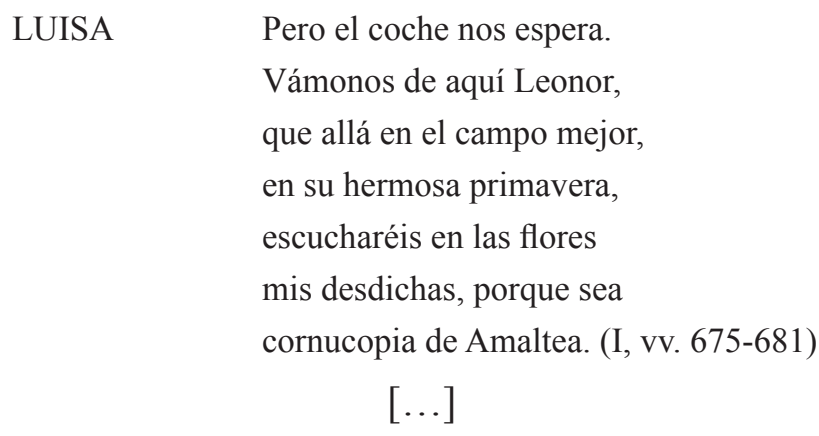

$\begin{array}{ll}\text { CARLOS } & \begin{array}{l}\text { Perdóname, doña Luisa, } \\ \text { si temerario me arrojo } \\ \text { a profanar de tu casa } \\ \text { el recato peligroso. (I, vv. 964-967) } \\ \text { FRISÓN }\end{array} \quad[\ldots] \\ & \begin{array}{l}\text { Venir a esta casa, Inés, } \\ \text { es querer con tu arrebol } \\ \text { hacella casa del sol } \\ \text { y de la luna después. (II, 1087-1090) }\end{array}\end{array}$

Finalmente encontramos referencias al espacio verbal referido a un lugar no escenificado. Sirvan como ejemplo un par de casos: primero, al comienzo de la obra el criado Frisón le describe a su amo la casa de la dama a quien ha entregado el papel encomendado por aquél,

$\begin{array}{ll}\text { FRISÓN } & \text { Señor, } \\ \text { profeta y embajador, } & \\ \text { lo fue solo san Gabriel. } & \text { Una casa autorizada, } \\ & \text { una escalera torcida, } \\ & \text { una antesala vestida } \\ & \text { y una puerta cerrada. }\end{array}$


Lacayos en el zaguán

y por el patio escuderos,

muchos pajes lisonjeros,

vestidos de tafetán,

$$
\text { [...] (I, vv. 212) }
$$

Segundo, Luisa marca este espacio oral cuando le dice a Estefanía:

LUISA Pero el coche nos espera,
vámonos de aquí, Leonor,
que allá en el campo mejor
en su hermosa primavera,
escucharéis en las flores
mis desdichas porque sea
cornucopia de Amaltea. (I, vv. 675-671)

Un elemento escenográfico de gran importancia en la comedia que nos ocupa es el balcón, que se construye mediante la abertura del corredor, que está situado en el segundo nivel del escenario de los corrales; es un elemento muy recurrente en la escenografía de las comedias de capa y espada, pues provoca la activación de tácticas escénicas, que permiten el avance de la acción dramática. El balcón marca el espacio de la calle, que es de dominio masculino, mientras que la casa es de lo femenino. Estoy de acuerdo con Carmen Josefina Pagnotta cuando dice:

En la comedia de enredo, la calle constituye el espacio abierto o público. Funcionalmente, es el medio de comunicación lógico entre las viviendas de los enamorados y adversarios. Los cortejantes realizan allí la ronda nocturna para acercarse a sus damas asomadas a las ventanas y balcones, y mantienen conversaciones ocultas con ellas. Allí, también, les confiesan sus sentimientos amorosos, a modo de soliloquios, o en diálogo con otros. A menudo, sacan las espadas y amenazan con batirse a duelo con algún oponente (Pagnotta, 2005, pp. 253).

En la jornada segunda, se anuncia con un escueto, Sale Leonor al balcón; ella cree que en realidad Carlos viene a declararle su amor, cuando el espectador sabe que tan solo viene a entregarle a Leonor una carta de parte de Enrique

LEONOR Don Carlos seré un diamante

en quererte, aunque en tu amor

me desprecie. (II, vv. 1403-1405) 
Es decir, el objetivo primordial de estos decorados es funcional, pues se trata de sugerir, como ocurría en el espacio interior, "sinecdóticamente el lugar donde se desarrolla la acción" (Ruano de la Haza, 2000, pp. 177).

La poca información escenográfica que de modo explícito aparece en Errar principios de amor, tal vez tenga su explicación en las escasas posibilidades reales que ofrecía el corral de comedias y concretamente en la configuración real del tablado que, en muchas ocasiones, solía tener unas dimensiones tan reducidas que impedían la posibilidad de llevar a cabo grandes alardes escenográficos.

\section{CONGLUSIÓN}

Errar principios de amor es una comedia de enredo, subgénero que debe mucho a autores como Lope de Vega, que explotó con éxito esta fórmula teatral, que continuó con brillantez Tirso de Molina y maduró en la segunda mitad del siglo XVII con dramaturgos tan destacados como Calderón, Rojas, Moreto, Ruiz de Alarcón o Rosete entre otros muchos.

Errar principios de amor constituye un magnífico ejemplo de la maestría de su autor, más allá de que se trate de una obra olvidada, una más de las muchas piezas de nuestro Siglo de Oro que todavía están esperando ver la luz, y que forman parte de nuestro rico e ingente patrimonio teatral español. Presenta valores indiscutibles que, en mi opinión, la hacen merecedora de una calidad teatral más que digna. Uno de los mayores logros se basa en la construcción de una trama ágil e ingeniosa en la que todo el peso de la acción recae no en dos parejas de enamorados, dos galanes y dos damas, como era lo habitual en las comedias de este tipo, sino en tres; esta estructura tripartita da lugar en la comedia a un conflicto intenso en el que se concentran amores cruzados, celos, juegos de escondite e identidades, que se funden y confunden en la complejidad de una trama, que se organiza en torno a dos intrigas principales y una más secundaria donde se suceden una serie de enredos que, como era de esperar, se solucionan con un final feliz. De igual modo, en esta comedia resulta muy atractiva la construcción de los personajes, insertos en un ambiente y en una configuración social y económica que no escapa a los ojos del espectador. Sobresalen especialmente las mujeres, que llevan la voz dominante -algo que funcionaba muy bien en escenacon una finalidad estrictamente teatral y muy alejada de cuestiones reivindicativas sobre el papel de la mujer en la sociedad de la época; esto hace que, a veces, se sienta una descompensación entre realidad y ficción en la que participan por igual autor y público. Asimismo, resulta acertado el inteligente manejo que hace el dramaturgo de una escenografía, más funcional que estética, donde se suceden las constantes entradas y salidas de los personajes que confieren un ritmo vertiginoso a la acción. 
Finalmente quiero destacar que, a pesar de no disponer de datos sobre la representación de Errar principios de amor, es seguro que Rosete la escribió para tal fin y del estudio de la misma se desprende una idea fundamental: el dramaturgo conoce perfectamente el teatro de su tiempo; sabe lo que hay que hacer para que una comedia funcione sobre las tablas y aplica todo su ingenio para proporcionarle al espectador, que acude al teatro, la posibilidad de soñar con un mundo alternativo que mejore su realidad. Así lo ha procurado el teatro en general y el barroco en particular -que ha sido capaz de sobrevivir a nuestro tiempo- antes, ahora y esperemos que lo siga haciendo siempre.

\section{BIBLIOGRAFÍA}

Alfonso Barrios, Andreu (2012). La construcción del espacio en las comedias de capa y espada de Calderón de La Barca. Madrid: Universidad Nacional de Educación a Distancia.

Antonucci, Fausta (2002). El espacio escénico y su representación en algunas comedias calderonianas de capa y espada. En Cazal, Françoise; González, Christophe y Vitse, Marc (eds,). Homenaje a Frédéric Serralta: el espacio y sus representaciones en el teatro español del Siglo de Oro. Pamplona: Universidad de Navarra: Iberoamericana: Vervuert, pp. 57-81.

Arellano, Ignacio (1999). La comedia de capa y espada: convención y rasgos genéricos. En Convención y recepción: estudios sobre el teatro del Siglo de Oro. Madrid: Gredos, pp. 37-69.

Barrera, Cayetano de la (1860). Catálogo bibliográfico y biográfico del teatro antiguo español desde sus orígenes hasta mediados del siglo XVIII. London: Támesis Books.

Calderón de la Barca, Pedro (s.a.). Bien vengas mal, si vienes solo. Sevilla: Imprenta de la viuda de Francisco de Leefdael.

Couderc, Christophe. El sistema de personajes en El acero de Madrid de Lope de Vega. Criticón, n. 87-88-89, pp.189-199.

Enríquez Gómez, Antonio (1656). Sansón Nazareno. Ruan: Imprenta de Laurenço Maurry.

Gutiérrez Gil, Alberto (2012). Componentes del enredo en la comedia de capa y espada de Rojas Zorrilla: "Primero es la honra que el gusto". Lectura y Signo, 7, pp. 243257.

Higashi Díaz, Óscar Alejandro (2013). La carta y el papel en la comedia de capa y espada de Calderón: género, enredo y suspenso. Anuario Calderoniano, 6, pp.183-198.

Huerta, Javier et al. (2005). Teatro español de la A a la Z. Madrid: Espasa-Calpe.

Lobato, $\mathrm{M}^{\mathrm{a}}$ Luisa (2011). Máscaras y juegos de identidad en el teatro español del Siglo de Oro. Madrid: Visor Libros. 
Mackenzie, Anne L. (1983). La escuela de Calderón. Estudio e investigación. Liverpool: Liverpool University Press.

Marín Diego (2006) (ed). Vega, Lope de. La dama boba. Madrid: Cátedra.

Menéndez Pelayo, Marcelino (1941). Calderón y su teatro. En Estudios y discurso de crítica histórica y literaria, III. Santander: CSIC, pp. 86-387

Moir, Duncan W. (ed.) (1970). Francisco A. Bances Candamo. Teatro de los teatros de los pasados y presentes siglos. London: Támesis.

Navarro Durán, Rosa (2003). Mecanismos del enredo en comedias de Francisco de Rojas. En Pedraza, Felipe B.; González Cañal, Rafael y Cano Navarro, José (eds.). Toledo, entre Calderón y Rojas: IV Centenario del nacimiento de don Pedro Calderón de la Barca, Toledo 14,15 y 16 de enero de 2000. 155-171 (Corral de Comedias; 14).

Pagnotta, Carmen Josefina (2005). Espacio e ingenio en la comedia de capa y espada de Tirso de Molina. En Iglesias Feijóo, Luis et. al. (eds.). Estudios de Teatro Español y Novohispano. Actas del XI Congreso de la Asociación Internacional de Teatro Español y Novohispano de los Siglos de Oro (septiembre 2003, Buenos Aires). Buenos Aires: Universidad de Buenos Aires, Facultad de Filología y Literaturas Hispánicas, pp. 243-255.

Paz y Melia, Antonio (1934). Catálogo de las piezas de teatro que se conservan en el departamento de manuscritos de la Biblioteca Nacional. $2^{\mathrm{a}}$ ed. Madrid: Blas Tipográfica, vol. 2.

Pedraza, Felipe B. y González Cañal, Rafael (eds.) (1998). La comedia de enredo: actas de la XX Jornadas de Teatro Clásico. Almagro, julio de 1997. Almagro: Universidad Castilla-La Mancha.

Pérez Magallón, Jesús (ed). (2011). Calderón de la Barca, Pedro. La dama duende. Madrid: Cátedra.

Ruano de la Haza, José María (2000). La puesta en escena de los teatros comerciales del Siglo de Oro. Madrid: Castalia.

Serralta, Frédéric (1988). El tipo de galán suelto: del enredo al figurón. Cuadernos de Teatro Clásico, n. 1, pp. 83-93.

Serralta, Frédéric (1998). El enredo y la comedia: deslinde preliminar. Criticón, n. 42, pp. 125-135.

Urzáiz Tortajada, Héctor (2002). Catálogo de autores teatrales del siglo XVII. Madrid: Fundación Universitaria Española, 2 vols.

Vigil, Mariló (1986). La vida de las mujeres en los siglos XVI y XVII. Madrid: Siglo Veintiuno.

Wardropper, Bruce W. (1978). "La comedia española del Siglo de Oro"; publicado a continuación de Eider Olson "Teoría de la comedia". Barcelona: Ariel.

Zugasti, Miguel (1997). De Enredo y teatro; algunas nociones teóricas y su aplicación a la obra de Tirso de Molina. En Pedraza Jiménez, Felipe B. y González Cañal, 
Errar principios de amor, una enredada y desconocida...- E. Domínguez de Paz

Rafael (coords.). La comedia de enredo: actas de las XX Jornadas de Teatro Clásico, Almagro, 8, 9 y 10 de julio. Castilla-La Mancha: Universidad de CastillaLa Mancha, pp. 109-141. 